of jewellery; decision regarding the nature of the principal gift awaits the intimation of Prof. Baker's wishes. It is known, however, that Prof. Baker, whose interest in the establishment of the College hostel has resulted in so marked a development in the students' social life, is anxious to commemorate his association with the Imperial College by placing a clock in the quadrangle, and intends to devote the major part of the presentation fund to that purpose.

\section{New Buildings at Rothamsted}

THe annual inspection of the experimental plots and laboratories at Rothamsted on June 21 was made the occasion of the official opening of a new block of buildings at the farm and the inauguration of an extensive electrical installation in the farm buildings. The Right Hon. Sir John Gilmour, Minister of Agriculture, declared the buildings open, in the presence of a large gathering of guests representing all branches of agriculture and the allied industries, and many of the visitors came from distant parts of the Empire. The new block of buildings will serve both the field experimental and demonstration sides of the farm. It contains an artificial manure store, working and office accommodation for the field experimental staff, and equipment to deal with the drying and preparation of the numerous samples taken in the course of the modern experiments. The purpose of the demonstration room is to facilitate the presentation of the field results which have direct practical interest in a way which is easily grasped by visitors. Diagrams and models take the place of tables of figures. Good types of machinery are illustrated, successful rations fed on the farm are on record, and exhibits of plant disease are set up as they become available. The electrical installation, designed by the General Electric Company, Ltd., will be of the most moderm and complete kind, and will provide very valuable information as to the cost and general efficiency of motor-driven farm machinery in comparison with the older oildriven type. The many visitors to Rothamsted are always interested in the excellent collection of modern implements loaned or presented by the makers. The installation of electrical equipment will greatly add to the demonstration value of this side of the farm.

\section{Southern Railway Electrification}

APPRECIABLE progress is being made on the Southern Railway's London-Brighton electrification scheme. According to the Electrician of June 24, 'stream. lined' electric trains have been undergoing night time tests. The first half of the new scheme-the extension to Three Bridges-will be opened on July 17. Thirtythree new trains will be employed, fitted with high speed motors and stream-lined, so that speeds of 70 miles an hour will be possible. The third class compartments have been built like the old first class compartments, and extra width has been given to the seats. The coaches have been built to the maximum width limit of the track, so it is impossible to use the 'bay window' type of look-out for the guard. The guards will see the signals through a periscope which projects through the roof. The signalling system has been changed throughout the route from the semaphore to the colour-light type. Whenever a train passes, the signals are automatically put to danger. An ingenious device is fitted in every signal-box which enables the signalman to know the exact nature of the trains that are approaching and their times. From July 17 there will be 61 trains running daily from London to Three Bridges, compared with 27 at present, while Three Bridges will have 57 trains to London in place of 19. The fastest trains have been timed to do the 30 miles in 39 minutes, but the average time for all the trains has been reduced from 60 to 52 minutes. The second stage of the scheme will probably be completed by March next.

\section{Gyro-stabilisers for Liners}

Authough the theory of the gyroscope has been taught for more than fifty years in several universities, it is only recently that the instalment of gyrostabilisers for ships, yachts, and aircraft carriers has begun to be adopted. The largest gyro-stabilising plant in the world has recently been completed for the new 46,000-ton luxury Italian liner Conte-di-Savoia at the works of Messrs. Vickers, Armstrong, Ltd., Barrow-in-Furness. An interesting account of the plant is given in the Metropolitan-Vickers Gazette for April. The plant consists of three identical stabiliser equipments, each one of which can function as a stabiliser independently of the other two. The rotating element in each consists of two solid forged steel disks. The rotating part (the rotor) weighs 110 tons and at normal working speeds it rotates at 910 revolutions per minute, being driven by a spinning electric motor mounted directly on the shaft. This motor is of the three-phase type and gives 560 horse-power at the normal speed. It is capable of giving 750 horsepower for 90 minutes during the accelerating period. The Sperry gyro-stabiliser is used, and this never allows the vessel to start rolling. A single wave can start a roll. In an unstabilised vessel, should the period of the rolling swings and the waves be the same, resonance might occur, and if the damping were small the rolling might become dangerous. Usually, however, the waves are only synchronous with the ship's natural swing for a brief period, and so its maximum swing is due to the accumulated effects of the waves. The Sperry device quenches the effects of these waves one by one, and so the stresses and strains on the hull of a stabilised ship are comparatively slight.

\section{Human Improvability}

Dr. C. S. MYERS contributes an article on " Human Improvability " to a recent issue of the Bristol MedicoChirurgical Journal (vol. 49, No. 183). He says that the problem of human improvability is as interesting as it is difficult. One difficulty lies in the definition of improvement, which is not necessarily synonymous with progress, and for which we can have only subjective criteria. The prevailing biological view is that all changes in living form and function are evoked by accident, and are perpetuated by heredity and by their suitability to the environment; improvement might then be regarded as involving a more perfect adaptation to the physical and social environment.

No. 3270 , VoL. 130] 
Some thinkers, however, find such a view inadequate to account for the facts, and therefore postulate in addition some, to us unknown, purpose in the universe. Our developing knowledge of other peoples has replaced many illusions as to natural differences by the recognition of likenesses as well, and confirms the importance of the social environment. It is not unlikely that man's mental and moral development depends in part upon the relation between his inheritance and the physical and social environment in which he grows up. Dr. Myers analyses several modern environmental conditions and concludes that changes have occurred which justify a belief in human improvability; these improvements do not, however, appear to come from the innate improvability of a race but from the improvement in the social heritage. The paper is provocative and stimulating, and in view of Dr. Myers's intimate knowledge of many aspects of modern civilisation, it is worthy of very serious consideration. It is all the more important at the present time, when so much pessimism is shown in the interpretation of the changes which our environment is experiencing.

\section{British Poisonous and Edible Plants}

ExcEPTING works on poisonous plants from the agricultural and medical points of view, there is very little printed information available to the lay reader. Fortunately, most British poisonous plants are rare; but the most dangerous are those with an attractive and luscious appearance. Perhaps that is why, despite their scarcity, such plants are the cause of illness and even death to unwary ramblers, campers, and school children every year. The pamphlet recently published as a reprint from School Nature Study therefore comes as a timely warning, not only to the country child and the town child in the country, for whom it is written, but also to adults who take an active part in country life. The pamphlet," British Poisonous and Edible Plants", written by Miss Hilda F. Rendle, after a few introductory remarks, gives a list of edible plants found growing wild. These are divided into black fruits, scarlet fruits, seeds and nuts, flowers, leaves, roots, and fungi. The second part deals with the poisonous plants, giving not only the well-known plants such as laurel, bryony, deadly nightshade, etc., but also some of the less familiar types such as the spindle with its attractive pink fruit and orange seeds, potato 'apples', and acorns. A few of these are illustrated. It is a pity that the fungi were not given more space. Only the common mushroom (Psallista) is described, with the concluding remark that "all other fungi should be avoided". In the present day of extended country activities, this pamphlet should be welcomed by all school teachers, boy scouts troops, country rambling organisations, etc. Copies at $2 \frac{1}{2} d$. each or two shillings per dozen can be obtained from Mr. E. G. Clarke, 7 Stanley Avenue, Wembley, Middlesex.

\section{Acquisitions at the Natural History Museum}

The Department of Botany, British Museum, has received 320 plants collected by Mr. H. St. J. B. Philby, on his recent Arabian journey and presented by the King of Hejaz and Najd. The plants are of interest botanically as being from an area previously unexplored. It has to be remembered that, from an economic point of view, plants are of the greatest importance in deserts, and according to Mr. Philby the Arabs know them so well as camel food or otherwise that they are able to judge the date of the last rains from their presence or absence. The Arab name is attached to each plant. Acquisitions of the Department of Minerals include meteorites collected by Mr. Philby, a piece from the 15-ton mass of meteoric iron discovered in 1930 near Mbosi in Tanganyika Territory, a piece of a meteoric stone which fell recently near Kirkuk, Iraq, and a specimen of pitchblende from the recently discovered occurrence on the Great Bear Lake, North-West Territory, Canada. Dr. Robert Broom has presented to the Geological Department a small series of South African fossil reptiles, several of which are the types of genera and species recently established by the donor. They belong principally to Therocephalian and Dicynodont genera, and range from Permian to Trias in age. Through the generosity of Rear-Admiral H. Lynes, Mr. Jack Vincent has been collecting for the Museum in Portuguese East Africa, the birds of which are very little known; already two consignments have been received. A collection of more than a thousand birds from Yunnan obtained by the late Mr. G. Forrest, the well-known plant collector, has been presented by the Godman Exploration Fund, while Dr. P. A. Buxton has presented a collection of some 750 birds made by him during the War in Iraq and Persia.

\section{Publications of the Institut Henri Poincaré}

THE completed first volume of the Annales de l'Institut Henri Poincaré (Paris: Institut Henri Poincaré ; Les Presses Universitaires de France) contains a highly interesting set of papers on theoretical physics and its mathematical borderland, of varying degrees of difficulty, several of which have been referred to in our columns on their appearance. The contributions verging on the purely mathematical include two on integral equations, by Kostitzin and Carleman, one by Brillouin, on a hyperbolic equation, and two, by Lévy and Polya, on the calculus of probabilities. Relativity is represented by Einstein and de Donder, and quantum theory by Darwin, Fermi, Born, and Dirac. The other papers are by Brillouin, on fusion, and by L. Bloch, on band spectra. It will be evident that the list of authors is one of unusual authority, a feature continued in the first numbers of the second volume by the inclusion of Sommerfeld and Cabrera. Their respective papers also give in short the aim of all, which appears to be to comment on current problems, or to collect and criticise otherwise scattered work. The papers are based on lectures delivered under the auspices of the Institut Henri Poincaré, and the only important change to be desired is that less time should be allowed to elapse between the delivery of the lecture and the time when it appears in print.

\section{Population of England and Wales}

The "Text" (final) volume of the RegistrarGeneral's Statistical Review, England and Wales, 1930, has been published (H.M. Stationery Office, $2 s .6 d$. 